\title{
Imbalanced Distribution of Plasmodium falciparum EBA-I 75 Genotypes Related to Clinical Status in Children from Bakoumba, Gabon
}

\author{
Fousseyni S. Touré, PhD; C. Bisseye and Elie Mavoungou, PhD
}

\begin{abstract}
Objective: The erythrocyte binding antigen $175 \mathrm{kDa}$ (EBA- I75) of Plasmodium falciparum is one of the major ligands for red blood cell invasion by merozoites. EBA-I75 is a dimorphic antigen but the role that dimorphism plays in host parasite interaction is not fully understood. In this study, we sought to determine the distribution of EBA-I75 genotypes and its pathogenetic influence.
\end{abstract}

Methods: The nested polymerase chain reaction was used to determine the genotypes of $P$. falciparum isolates from asymptomatic and symptomatic Gabonese children.

Results: CAMP strains (C-segment) and FCR-3 strains (F-segment) were found in 13/50 (26\%) and $19 / 50$ (38\%) symptomatic children, respectively and in $16 / 66(24 \%)$ and $46 / 66(70 \%)$ asymptomatic children, respectively. The prevalence of mixed C-/F- infection was $18 / 50$ (36\%) and 4/66 (6\%) in symptomatic and asymptomatic children, respectively.

Conclusions: These results show that mixed C-/F- infection is associated with clinical malaria $\left(\chi^{2}, P<0.01\right)$ and may have important therapeutic implications.

Keywords: CAMP strains; Erythrocyte binding antigen 175 kDa; FCR-3 strains; Plasmodium falciparum

$\mathrm{T}$ he antigenic diversity of Plasmodium falciparum is the main obstacle to antimalarial vaccine development. Erythrocyte-binding antigen $175 \mathrm{kDa}$ (EBA-175), expressed on the merozoite surface, is involved in P. falciparum binding to erythrocytes. ${ }^{1-5}$ In animal models, immunization with synthetic EBA-175 peptides encompassing amino acids 1062 to 1103 elicits antibodies that inhibit merozoite invasion by $80 \%$ in vitro. These antibodies appear to act by preventing EBA-175 binding to erythrocytes. ${ }^{6}$ In addition, a significant reduction in parasitemia was recently reported in monkeys immunized with EBA-175.7

EBA-175 is composed of 7 regions (region I-VII) and possesses 2 cysteine-rich segments (F1 and F2) located at the $\mathrm{N}$-terminus in region II (figure 1). These cysteine-rich segments, F1 and F2, are responsible for glycophorin A binding to the erythrocyte membrane ${ }^{4}$ and contain a very small number of polymorphic regions. EBA-175 region III is located in the central part of the gene, and genomic studies of two P. falciparum strains revealed two highly dimorphic segments in region III, named FCR-3 and CAMP.5,8,9 Dimorphism is referred to as the F-fragment in the FCR-3 strain and the $\mathrm{C}$-fragment in the CAMP strain. The two segments are inserted at different positions of region III and differ in length by 27 amino acids. These two alleles are both conserved, and Plasmodium merozoites, which are haploid, can possess one or the other, but not both.

The role of EBA-175 antigen dimorphism in host-parasite interactions is not fully understood. Preliminary evidence suggests that the initial molecular interaction involves binding of the conserved domain (region II of EBA-175) to glycophorin A sialic acid residues, followed by proteolytic cleavage of EBA-175 and binding of the dimorphic C- and F- segments to the glycophorin A backbone. ${ }^{8,9}$ Likewise, the role of this dimorphism in acquired protective immunity to field strains is not known. It was recently shown that EBA-175 is able to use
Reprint Requests: Dr. E. Mavoungou, PhD; Medical Research Unit, Albert Schweitzer Hospital, Lambaréné, Gabon; c/o Institute for Tropical Medicine, Department of Parasitology, University of Tübingen, Wilhelmstrasse 27, 72074 Tübingen, Germany; Tel: 707I/298 21 94; Fax: 707I/29 58; Email: elie.mavoungou@uni-tuebingen.de

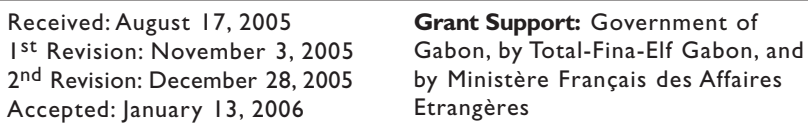




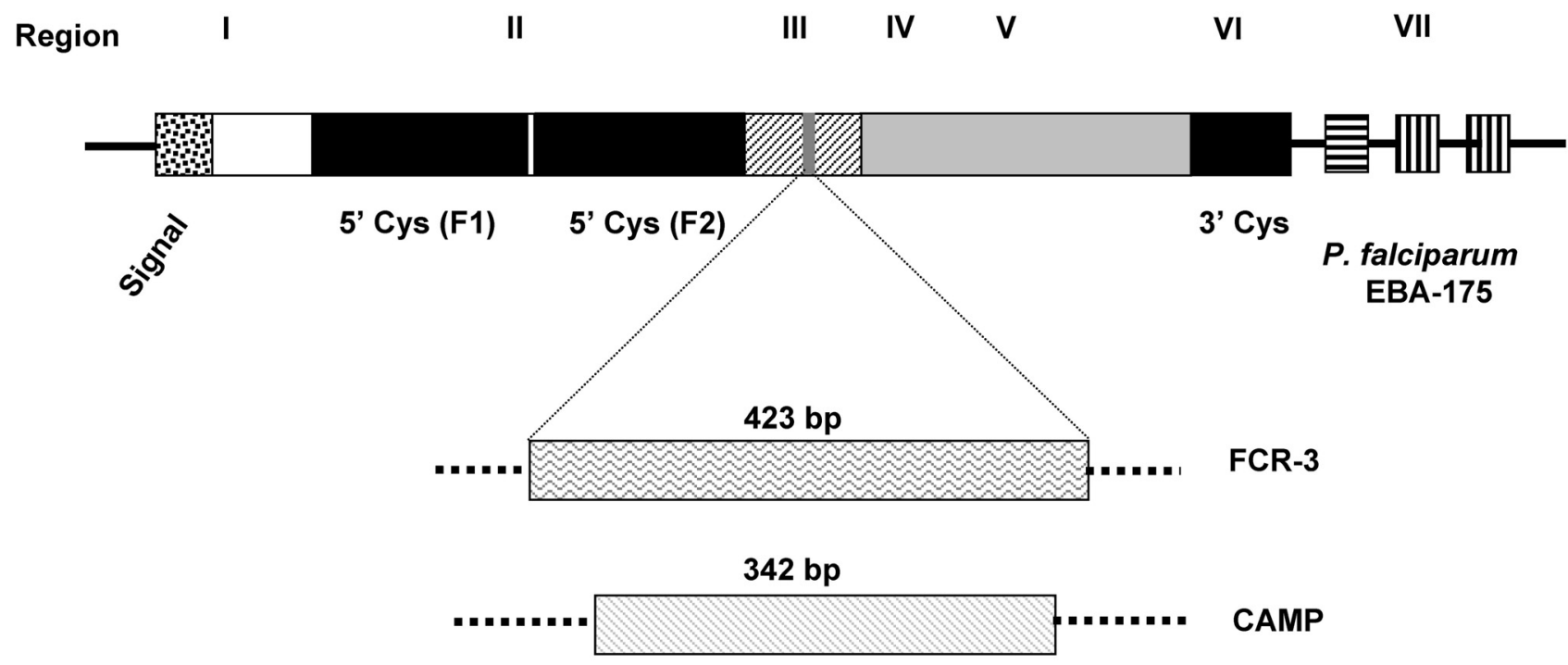

Figure 1. Structure of the EBA-175 gene in P. falciparum showing the divergent region III composed of the CAMP segment, 342 base pairs (bp) and the FCR-3 segment, $423 \mathrm{bp}$.

both sialic and non sialic pathways. ${ }^{10}$ We have previously refined EBA-175 genotyping by using nested polymerase chain reaction (PCR) and a set of primers specific to both genotypes. ${ }^{11}$ In this study, we compared the EBA-175 loci of $P$. falciparum strains isolated from asymptomatic and symptomatic children living in Bakoumba, Gabon.

\section{Patients and Methods}

Study site

This study took place in Bakoumba (Haut Ogooué Province), a town in southeast Gabon. Preliminary studies showed that P. falciparum transmission is moderate and perennial, with only minor seasonal fluctuations (Touré FS, unpublished data). The main vectors in this area are Anopheles gambiae and Anopheles funestus with $P$. falciparum responsible for approximately $95 \%$ of all diagnosed cases of clinical malaria. The entomological inoculation rate has not yet been established.

\section{Ethical clearance}

This study was approved by the ethics committee of the International Centre for Medical Research in Gabon and was performed in accordance with guidelines for human experimentation published by the Gabonese Ministry of Public Health and Population. Informed consent was obtained from the parents or guardians of all participating children.

\section{Blood sampling}

Three hundred children from three schools were monitored between March and July 2001 for P. falciparum malaria infection. All the children were screened for $P$. falciparum infection by fingerprick blood sampling on day 0 , every 2 weeks thereafter and whenever fever occurred. Blood was collected by venipuncture from all $P$. falciparum-infected children using EDTA Vacutainers ${ }^{\circledR}$ (Becton Dickinson, Meylan, France).

\section{Diagnosis}

Thick and thin blood films were Giemsa-stained and examined by two readers using standard quality-controlled procedures. ${ }^{12}$ Parasite load was expressed as the number of asexual forms of $P$. falciparum per microliter of blood. All infected children displaying symptoms of malaria were treated with quinine $(24 \mathrm{mg} / \mathrm{kg} /$ day $/ 7$ days $)$ according to local hospital guidelines.

\section{Study population}

Children, age 6 to 15 years, with uncomplicated malaria were matched for age, gender and place of residence. The children asymptomatically infected (asymptomatics) had fewer than 5000 asexual blood stage parasites per microliter of blood, an axillary temperature below $37.5^{\circ} \mathrm{C}$ on the day of recruitment, no history of fever in the 24 hours before or the week after recruitment, and were free of sickle cell disease. Their hemoglobin level was more than $10 \mathrm{~g} / \mathrm{dl}$ and/or their hematocrit was more than $30 \%$. The children with uncomplicated malaria (symptomatic) all had an axillary temperature $\geq 37.5^{\circ} \mathrm{C}$, between 5000 and 250,000 parasites $/ \mu 1$ of blood, a hemoglobin level $\geq 5$ but $<10 \mathrm{~g} / \mathrm{dl}$, and were free of sickle cell disease. These children had no concomitant active infections and did not have severe malaria as defined by the World Health Organization (WHO). ${ }^{13}$

\section{EBA-175 genotyping}

The EBA-175 genotype was determined by nested PCR as described elsewhere. ${ }^{11}$

\section{Statistical analysis}

Analyses were performed using StatView for Windows 5.01 (SAS Institute Inc., Cary, NC). Differences were considered significant if two-tailed $P$ values were $<0.05$. 


\section{Results}

One hundred sixteen (38.7\%) of the 300 children were infected by $P$. falciparum. Fifty children had symptomatic malaria and 66 had asymptomatic infection. Average age of symptomatic and asymptomatic children was 11.3 and 11.2 years, respectively. The geometric mean parasite loads for symptomatic and asymptomatic children was $9613 / \mu 1$ and $948 / \mu 1$, respectively.

Thirteen (26\%) of the 50 isolates from children with symptomatic infection were CAMP-positive and 19 (38\%) were FCR-3-positive (figure 2). CAMP/FCR-3 mixed infection was detected in the 18 remaining samples (36\%). Sixteen $(24 \%)$ of the 66 samples from children with asymptomatic infection were CAMP-positive, 46 (70\%) were FCR-3-positive and 4 (6\%) were positive for both CAMP and FCR-3. In single infections, the FCR-3 genotype predominated irrespective of the sampling period and clinical status ( $P<0.001$, Mann-Whitney $U$ test). A significant association was found between mixed C-/F- infection and symptomatic malaria (Cochran's chi-square of 0.30 on 1 degree of freedom of linear trend for proportions; $P<0.01$ ) (figure 2). No correlation was found between age and either mixed infection or parasite load (not shown).

\section{Discussion}

$P$. falciparum genotyping can help to unravel host-parasite interactions, including strain-specific immune responses. Previous studies of merozoite genes (MSA-1 and MSA-2) demonstrated that some patients were infected by more than one genotype ${ }^{14-17}$ and have also identified genotypes associated with clinical malaria. ${ }^{18,19}$ However, the results of MSA-1 and MSA-2 genotyping have shown major geographic variations. ${ }^{20}$ In this study we used a dimorphic marker, EBA-175, which greatly simplified data analysis (see figure 1). This study is the first to analyze the EBA-175 allelic dimorphism among pediatric $P$. falciparum isolates according to clinical status. The CAMP and FCR-3 genotypes were encountered in both symptomatic and asymptomatic patients, but the FCR-3 genotype predominated regardless of clinical status and the sampling period. In total, $77 \%(89 / 116)$ were carrying the FCR-3 fragment. Our data indicate that the FCR-3 genotype is more prevalent in Bakoumba, which is consistent with a previous study that showed a higher frequency $(>70 \%)$ of the F-fragment in central and western African populations. ${ }^{21,22}$ However, we found that the frequency of coinfection was far higher in symptomatic subjects than in asymptomatic subjects, whereas Cramer et $\mathrm{al}^{22}$ found fewer cases of coinfection in children with severe malaria than in asymptomatic children. Significant differences in EBA-175 genotype distribution between the north and the south province of the Lao People's Democratic Republic have also been reported. ${ }^{23}$ Together, these results suggest that the distribution of EBA-175 genotypes between different clinical groups differs across geographic regions.

The difference between the symptomatic and asymptomatic children in our study was not related to the sickle-cell trait,

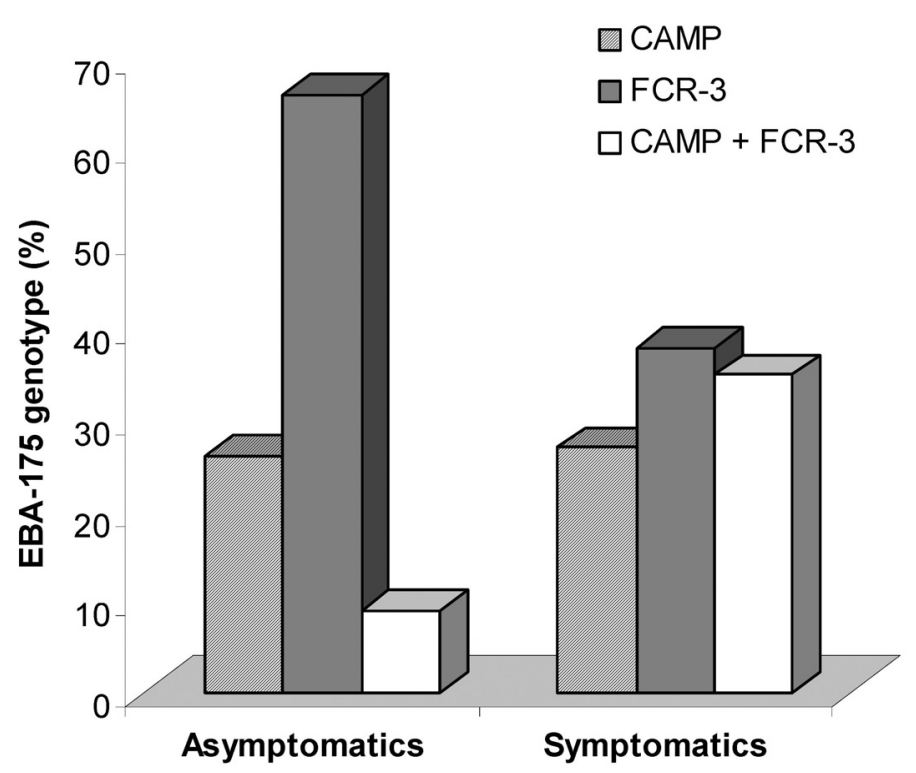

Figure 2. Distribution of EBA-175 genotypes in Gabonese children with symptomatic and asymptomatic $P$. falciparum infection.

which is associated with multiple genotype infections. ${ }^{24}$ The possibility that other genetic characteristics influence the risk of coinfection was not studied here. In addition, although our method permits EBA-175 genotyping of all samples that are positive by direct examination, the possibility that a minor allele was not detected in some cases of coinfection cannot be ruled out.

Symptomatic malaria appears to be due to parasite genotypes that the host has not yet encountered and to a resulting lack of specific immunity. ${ }^{25,26}$ If an individual encounters a CAMP or FCR-3 strain for the first time, he or she may develop specific antibodies (if not major histocompatibility complex [MHC]-restricted) and may thus remain asymptomatic. When an individual encounters genotypes CAMP and FCR-3 simultaneously for the first time, he or she may develop immunity to both strains and remain asymptomatic. In such cases, antibodies directed against the two genotypes inhibit erythrocyte invasion by merozoites.

In our study, children infected by both the CAMP and FCR-3 genotypes were very often symptomatic suggesting that they had no acquired immunity. These children may thus be protected against one genotype but not both, possibly due to $\mathrm{MHC}$ restriction.

Coinfection can be due to a single mosquito bite if the mosquito was carrying the two parasite genotypes or due to two different bites where each mosquito transmitted one particular genotype. This latter scheme may occur frequently in areas with a high entomological inoculation rate. It would be interesting to analyze the specific humoral response to the CAMP and FCR-3 strains according to clinical status. On the basis of our results, we would expect antibody titers against 
the two alleles to be higher in asymptomatic coinfected subjects than in their symptomatic counterparts.

Specific immunity to allele EBA-175 cannot alone prevent $P$. falciparum multiplication for several reasons. First, most field isolates use molecules other than EBA-175 to invade red cells. ${ }^{27}$ Second, it was recently shown that $P$. falciparum can switch its invasion phenotype, thereby avoiding the host response and becoming virulent. ${ }^{28}$ This points to the existence of virulence factors associated with clinical status and/or severe malaria that can co-segregate with EBA-175.

In conclusion, this comparative analysis of the allelic dimorphism of EBA-175 antigen in $P$. falciparum isolates from Gabonese children shows a significant association between coinfection and clinical status. If confirmed, these findings should be taken into account in antimalarial strategies.

\section{Acknowledgments}

We are grateful to the children and their parents and guardians for participating in the study and to the staff of the Centre International de Recherches Médicales de Franceville Parasitology Unit. We also thank Dr. Florence Migot-Nabias for her helpful suggestions.

\section{References}

1. Camus D, Hadley TJ. A Plasmodium falciparum antigen that binds to host erythrocytes and merozoites. Science 1985;230:553-556.

2. Klotz FW, Orlandi PA, Reuter G, Cohen SJ, Haynes JD, Schauer R, Howard RJ, Palese P, Miller LH. Binding of Plasmodium falciparum 175-kilodalton erythrocyte binding antigen and invasion of murine erythrocytes requires $\mathrm{N}$-acetylneuraminic acid but not its $\mathrm{O}$-acetylated form. Mol Biochem Parasitol 1992;51:49-54

3. Orlandi PA, Klotz FW, Haynes JD. A malaria invasion receptor, the 175-kilodalton erythrocyte binding antigen of Plasmodium falciparum recognizes the terminal Neu5Ac(alpha 2-3)Gal- sequences of glycophorin A. J Cell Biol 1992;116:901-909.

4. Sim BK, Chitnis CE, Wasniowska K, Hadley TJ, Miller LH. Receptor and ligand domains for invasion of erythrocytes by Plasmodium falciparum. Science 1994;264:1941-1944.

5. Sim BK. EBA-175: an erythrocyte-binding ligand of Plasmodium falciparum. Parasitol Today 1995;11:213-217.

6. Sim BK, Orlandi PA, Haynes JD, Klotz FW, Carter JM, Camus D, Zegans ME, Chulay JD. Primary structure of the $175 \mathrm{~K}$ Plasmodium falciparum erythrocyte binding antigen and identification of a peptide which elicits antibodies that inhibit malaria merozoite invasion. J Cell Biol 1990;111:1877-1884.

7. Jones TR, Narum DL, Gozalo AS, Aguiar J, Fuhrmann SR, Liang H, Haynes JD, Moch JK, Lucas C, Luu T, Magill AJ, Hoffman SL, Sim BK. Protection of Aotus monkeys by Plasmodium falciparum EBA-175 region II DNA prime-protein boost immunization regimen. J Infect Dis 2001;183:303-312.

8. Kain KC, Orlandi PA, Haynes JD, Sim KL, Lanar DE. Evidence for two-stage binding by the $175-\mathrm{kD}$ erythrocyte binding antigen of Plasmodium falciparum. J Exp Med 1993;178:1497-1505.
9. Ware LA, Kain KC, Lee Sim BK, Haynes JD, Baird JK, Lanar DE. Two alleles of the 175-kilodalton Plasmodium falciparum erythrocyte binding antigen. Mol Biochem Parasitol 1993;60:105-109.

10. Duraisingh MT, Maier AG, Triglia T, Cowman AF. Erythrocyte-binding antigen 175 mediates invasion in Plasmodium falciparum utilizing sialic acid-dependent and independent pathways. Proc Natl Acad Sci U S A 2003;100:4796-4801.

11. Touré FS, Mavoungou E, Ndong JM, Tshipamba P, Deloron P. Erythrocyte binding antigen (EBA-175) of Plasmodium falciparum: improved genotype determination by nested polymerase chain reaction. Trop Med Int Health 2001;6:767-769.

12. Planche T, Krishna S, Kombila M, Engel K, Faucher JF, Ngou-Milama E, Kremsner PG. Comparison of methods for the rapid laboratory assessment of children with malaria. Am J Trop Med Hyg 2001;65:599-602.

13. [No authors listed]. Severe falciparum malaria. World Health Organization, Communicable Diseases Cluster. Trans R Soc Trop Med Hyg 2000;94:S1-90.

14. Babiker HA, Creasey AM, Fenton B, Bayoumi RA, Arnot DE, Walliker D. Genetic diversity of Plasmodium falciparum in a village in eastern Sudan. 1. Diversity of enzymes, 2D-PAGE proteins and antigens. Trans R Soc Trop Med Hyg 1991;85:572-577.

15. Conway DJ, Greenwood BM, McBride JS. The epidemiology of multiple-clone Plasmodium falciparum infections in Gambian patients. Parasitology 1991;103 Pt 1:1-6.

16. Ntoumi F, Contamin H, Rogier C, Bonnefoy S, Trape JF, Mercereau-Puijalon O. Age-dependent carriage of multiple Plasmodium falciparum merozoite surface antigen-2 alleles in asymptomatic malaria infections. Am J Trop Med Hyg 1995;52:81-88.

17. Beck HP, Felger I, Huber W, Steiger S, Smith T, Weiss N, Alonso P, Tanner M. Analysis of multiple Plasmodium falciparum infections in Tanzanian children during the phase III trial of the malaria vaccine SPf66. J Infect Dis 1997; 175:921-926

18. Robert F, Ntoumi F, Angel G, Candito D, Rogier C, Fandeur T, Sarthou JL, Mercereau-Puijalon O. Extensive genetic diversity of Plasmodium falciparum isolates collected from patients with severe malaria in Dakar, Senegal. Trans R Soc Trop Med Hyg 1996;90:704-711.

19. Engelbrecht F, Felger I, Genton B, Alpers M, Beck HP. Plasmodium falciparum: malaria morbidity is associated with specific merozoite surface antigen 2 genotypes. Exp Parasitol 1995;81:90-96.

20. Konate L, Zwetyenga J, Rogier C, Bischoff E, Fontenille D, Tall A, Spiegel A, Trape JF, Mercereau-Puijalon O. Variation of Plasmodium falciparum msp1 block 2 and msp2 allele prevalence and of infection complexity in two neighbouring Senegalese villages with different transmission conditions. Trans R Soc Trop Med Hyg 1999;93:21-28.

21. Binks RH, Baum J, Oduola AM, Arnot DE, Babiker HA, Kremsner PG, Roper C, Greenwood BM, Conway DJ. Population genetic analysis of the Plasmodium falciparum erythrocyte binding antigen-175 (eba-175) gene. Mol Biochem Parasitol 2001;114:63-70.

22. Cramer JP, Mockenhaupt FP, Mohl I, Dittrich S, Dietz E, Otchwemah RN, Ehrhardt S, Bienzle U, Jelinek T. Allelic dimorphism of the erythrocyte binding antigen-175 (eba-175) gene of Plasmodium falciparum and severe malaria: significant association of the C-segment with fatal outcome in Ghanaian children. Malar J 2004;3:11.

23. Dittrich S, Schwobel B, Jordan S, Vanisaveth V, Rattanaxay P, Christophel EM, Phompida S, Jelinek T. Distribution of the two forms of Plasmodium falciparum erythrocyte binding antigen-175 (eba-175) gene in Lao PDR. Malar J 2003;2:23. 
24. Ntoumi F, Mercereau-Puijalon O, Ossari S, Luty A, Reltien J, Georges A, Millet P. Plasmodium falciparum: sickle-cell trait is associated with higher prevalence of multiple infections in Gabonese children with asymptomatic infections. Exp Parasitol 1997;87:39-46.

25. Ntoumi F, Ngoundou-Landji J, Luty AJF. Polymorphisme allélique du gène MSP-2 de Plasmodium falciparum analyse à parird échantillons sanguins d'enfants gabonais. Bull Soc Pathol Exot 2001;94:183-187.

26. Ofosu-Okyere A, Mackinnon MJ, Sowa MP, Koram KA, Nkrumah F, Osei YD, Hill WG, Wilson MD, Arnot DE. Novel Plasmodium falciparum clones and rising clone multiplicities are associated with the increase in malaria morbidity in Ghanaian children during the transition into the high transmission season. Parasitology 2001;123:113-123.

27. Lobo CA, de Frazao K, Rodriguez M, Reid M, Zalis M, Lustigman S. Invasion profiles of Brazilian field isolates of Plasmodium falciparum: phenotypic and genotypic analyses. Infect Immun 2004;72:5886-5891.

28. Stubbs J, Simpson KM, Triglia T, Plouffe D, Tonkin CJ, Duraisingh MT, Maier AG, Winzeler EA, Cowman AF. Molecular mechanism for switching of $P$. falciparum invasion pathways into human erythrocytes. Science 2005;309:1384-1387.

\section{Author Affiliations}

Fousseyni S. Touré, PhD, Centre International de Recherches Médicales de Franceville, BP 769 Franceville, Gabon.

C. Bisseye, PhD student, Centre International de Recherches Médicales de Franceville, BP 769 Franceville, Gabon.

Elie Mavoungou, PhD, Medical Research Unit, Albert Schweitzer Hospital, Lambaréné, Gabon and Institute for Tropical Medicine, Department of Parasitology, University of Tübingen, Germany. 